no evidence of the discontinuity expected from the segregation of one or a few genes of major effect.

The analysis employed displays lack of discrimination between dominance and potence, which would not matter if one accepts single gene interpretations throughout. The authors regularly determine dominance from the $F_{1}$ mean, following the unfortunate and incorrect view, which has been propagated in the behavioural literature by Bruell, that the coincidence of the $F_{1}$ mean and the mid-parent value implies no dominance, whereas this estimate of potence can be explained in several alternative and illuminating ways, which in fact invoke dominance.

Within the restrictions of possible inadequacies of scale and of their earlier assumptions, the numerous estimates of heritability which Scott and Fuller present are essentially satisfactory and establish beyond doubt the magnitude and importance of the heritable component of the behaviour studied. However, they always estimate environmental variation from the $F_{1}$ generation only, never using the comparable variances of the parents. This is unfortunate on two counts. First, it gratuitously discards half of the relevant data and, second, in the presence of unequal variances among parents and $F_{1}$ that is, when genotype-environmental interaction is present, all three must be used to give a valid estimate of environmental variation.

Despite these strictures, it is only fair to note that the authors explicitly recognise the limitations of the analytical methods they employed and realise the possibility of the application of more sophisticated methods. However, they doubt the applicability of such methods in the absence of genetic homogeneity in the parental breeds. But methods exist for dealing with such problems within the context of biometrical genetics, and it may well be that others will attempt their application to the rich collection of data on dog behaviour which Scott and Fuller have made available in this important book.

P. L. Broadhurst and J. L. Jinks.

\title{
APPENDIX EXTRAORDINARY
}

MENTAL RETARDATION: A FAMILY STUDY. Elizabeth W. Reed and S. C. Reed. W. B. Saunders, Philadelphia, 1965. Pp. vi+719. £7.

This book is mostly an appendix. The first 80 pages describe how the data were collected and the succeeding $65^{\circ}$ or so present them.

The research reported by Dr. Elizabeth Reed and her husband, who has been Director of the Dight Institute of Human Genetics at the University of Minnesota since I947, began as long ago as IgI I when two trained social workers began a study of the families of patients at a state institution in Minnesota. It was clearly extremely well carried out and, fortunately, intelligence tests were developed and applied early in this particular state, so that assessments of intelligence quotient are available for many of the probands in the study. In I 949 the study was reopened, and criteria carefully laid down as to which of the original families should be followed up. For example, epileptics were omitted from further consideration. The result is that no less than 80,000 people are included in this work, which is a sort of Kinsey report on mental retardation, and constitutes perhaps the most important study in this area for many years.

The authors wisely accept that, while the IQ measurements they present 
are not perfect, they constitute the one solid source of behavioural data available to them and, indeed, they instance many features of the data which support this conclusion and point to usefulness and, indeed, the stability of this measure.

The probable sources of bias in this vast collection of data are very carefully explored and some analyses performed on them. In their analyses of many aspects of the family dynamics of both the probands and their relatives, they present much of interest relating to reproduction, matters bearing on genetic counselling in relation to mental retardation, and the choice of mate as influenced by IQ. In all this only occasionally does their psychological judgement alter, as, for example, when they attribute lack of motivation of individuals of high IQ who are underachievers to unsatisfactory socio-environmental conditions. In their discussion of the relationship of intelligence to family size they claim to have resolved Cattell's paradox, which is that national intelligence is bound to decline because of the negative correlation between family size and IQ of parents. This is usually found to be of the order of -0.2 to -0.3 and, in their data, reaches the latter figure precisely. But, as Mather has pointed out, it is important to include childless members of the parental generation in any such assessment. Reed and Reed show that, when the reproductive rate of childless siblings of the retarded parents is also considered, the negative correlation disappears. Since these findings are based on numbers approaching 2000, this contribution to the resolution of the paradox seems to be of some importance.

But it is the body of the book which merits special attention. It consists of a series of genealogical trees of the families concerned, extending over as many as eight generations and often over more than roo years. These trees are masterpieces of the genealogist's art in the amount of data which is displayed in a relatively small compass. Even so, one family extends over nine pages of diagrams, and many of them contain several hundred and sometimes even thousands of individuals. Family relationships are clearly shown, together with IQs wherever these are available. One minor criticism is that the proband is occasionally difficult to find and, had colour printing been possible, it could have been used with advantage here. The notes on each family are concisely organised and present further details of the etiology of the retardation investigated and of the course of the enquiries made.

This meticulous presentation of the primary data on which the conclusions in the first section are based and the tentative classification of the retarded into various genetic and environmental categories are made is a tremendous strength of this book. It not only allows the interested reader to check the authors' conclusions, but will also provide a rich fund of data for others to analyse in any ways they choose. The present reviewer was excited by the possibility of analyses of intellectual capacity by the method of biometrical genetics, based on the techniques applicable to the successive matings of individuals in certain well-defined patterns, such as a man with several wives in turn, or the $2 \times 2$ diallel cross of individuals (double divorce and re-marriage). However, disappointingly few cases are to be found in the data presented by Reed and Reed, though numerous examples of siblings marrying siblings, and even well-established cases of incest, are available. But these "exotics" - to use a telling phrase of Cattell'sbecome increasingly rare in the later generations for which intelligence is 
more generally documented. Nevertheless, for any one interested in parentoffspring and sibling correlations for intelligence this body of data will be of extreme interest, and it is clear that many people will be greatly indebted to the authors for this first-class compilation so frankly presented.

\section{P. L. Broadhurst.}

\section{INNATE AND LEARNED}

EVOLUTION AND MODIFICATION OF BEHAVIOUR. K. Lorenz. Methuen, London, 1966. Pp. $122+$ vi. 25s.

Lorenz says he wrote this book " to prevent the discrediting of a concept . . . indispensable to an ethological approach. This concept is that of the innate." The ethological approach in zoology undoubtedly has had great influence on those concerned with behavioural work on animals since World War II. This essentially continental approach has now taken firm root in this country and produced some distinguished experimental work: its influence in America has been somewhat less widespread but is nevertheless considerable. Previously comparative psychologists were among the few concerned with the analysis of animal behaviour.

To support his aim Lorenz critically examines the history of recent discussions of the ethological concept of the innate. He takes the distinguished Canadian psychologist Hebb to task for his insistence that the dichotomy between what is innate and what is learned is a false one in that the two can only be distinguished by mutual exclusion. The spectacle of the two most recently elected Fellows of the Royal Society, thus honoured for their contributions to behavioural work, so contentiously engaged together dramatically highlights the divergencies between the two major approaches in this area, that of the ethologist and the animal psychologist.

Lorenz bases himself on a Darwinian position which, despite his characteristic strictures on psychologists who work with animals in the laboratory, is one which, I imagine, most animal psychologists would today be content to share. Lorenz clearly views learning as an individual recapitulation of the evolutionary process. This he tellingly calls "trial and success (not error)"-the process of selective adaptation which is now, I suppose, universally accepted as underlying evolutionary change. The unamended phrase, of course, is that of Thorndike, one of the pioneers of animal psychology whose studies of animal learning form part of that large body of work begun at the turn of the century in the United States and carried out continuously thereafter and which ethologists so frequently ignore in discussing the development of their own interest in innate behaviour which dates from more recent times. He is willing to correct the record by admitting that older ethologists did in fact fall into the error of minimising the role of learning, especially their neglect of the selective pressures attributable to the reinforcement principle. This principle, so central to much of learning theory, was first emphasised by Pavlov and was developed and extended by his American successors, such as Hull. But, in contradistinction to many modern ethologists, Lorenz persists in regarding some aspect of response in the organism as innately given and not subject to individual adaptation as a result of experience. Thus he appears to retain the view, which he characterises as being that of the older ethologists, that there may be " selfcontained units into which learning does not enter". 